\title{
Maryse Condé, Mets et merveilles
}

\section{Elena Fermi}

\section{OpenEdition}

\section{Journals}

\section{Édition électronique}

URL : http://journals.openedition.org/studifrancesi/5462

DOI : 10.4000/studifrancesi.5462

ISSN : 2427-5856

\section{Éditeur}

Rosenberg \& Sellier

\section{Édition imprimée}

Date de publication : 1 décembre 2016

Pagination : 578

ISSN : 0039-2944

\section{Référence électronique}

Elena Fermi, « Maryse Condé, Mets et merveilles », Studi Francesi [En ligne], 180 (LX | III) | 2016, mis en ligne le 01 janvier 2017, consulté le 18 septembre 2020. URL : http://journals.openedition.org/ studifrancesi/5462 ; DOI : https://doi.org/10.4000/studifrancesi.5462

\section{Ce document a été généré automatiquement le 18 septembre 2020.}

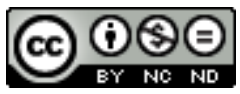

Studi Francesi è distribuita con Licenza Creative Commons Attribuzione - Non commerciale - Non opere derivate 4.0 Internazionale. 


\title{
Maryse Condé, Mets et merveilles
}

\author{
Elena Fermi
}

\section{RÉFÉRENCE}

MARYSE CONDÉ, Mets et merveilles, Paris, JC Lattès, 2015, pp. 384.

1 Autobiographie, récit de voyage, roman de formation et livre de cuisine à la fois, Mets et merveilles, le dernier ouvrage de Maryse Condé, constitue une suite à La vie sans fards (2012), où elle avait entamé l'autobiographie d'une femme à la recherche de son identité et à Victoire, les saveurs et les mots (2006), évocation de la vie de sa grand-mère maternelle. Dans les 377 pages de son dernier roman, Condé cherche à donner sa réponse à une question qui l'a tourmentée depuis son enfance: faut-il hiérarchiser la passion pour la littérature et celle pour la cuisine? L'approche intellectuelle, la profession d'écrivaine et de professeur universitaire, sont-ils supérieurs aux métiers de la table? Les deux passions ne peuvent-elles pas coexister chez une seule personne au même niveau et même se compléter l'une l'autre? La réponse que l'écrivaine guadeloupéenne donne est bien sûr affirmative. Ce livre - déclare-t-elle dans la préface (p.15) - est bel et bien le récit de son «long crime de lèse-majesté». Elle y entraîne justement le lecteur dans ses virées autour du monde, pérégrinations à la fois intellectuelles et gastronomiques. Les deux passions cohabitent et font partie intégrante de la personnalité de l'écrivaine qui, au fur et à mesure de ses découvertes, s'interroge sur elle-même, sur les moments de sa vie, sur son parcours de formation, de l'enfance à l'âge adulte et à la vieillesse, tout en menant des réflexions profondes sur les problématiques sociales, la littérature, la politique, l'histoire, dans un style épuré et agréable à lire. On la suit dans son errance de la Guadeloupe de son enfance à l'Afrique de ses racines, de l'Angleterre à la Jamaïque, de l'Inde au Japon, des États-Unis à Cuba et à l'Afrique du Sud. Chaque voyage est un voyage dans l'espace, dans les mots et dans les mets, car pour Condé, la cuisine est un art mais aussi un élément culturel de premier plan. Partout où son travail intellectuel la conduit au cours de sa vie, elle mène son enquête personnelle sur les plats qu'on peut y goûter et prend plaisir, une fois revenue chez elle, à les réinventer, les recréer car pour elle la cuisine est une zone franche dont 
les règles peuvent être réécrites. Les rencontres culinaires sont aussi, dans la plupart des cas, l'occasion de rencontres humaines, car partager la même table et les mêmes mets favorise souvent le partage des idées. Tout en ne contenant aucune recette, ce livre met les papilles en éveil, fait venir l'eau à la bouche, car il est plein de couleurs mais surtout d'odeurs et bien sûr de saveurs du monde entier. Maryse Condé y fait aussi ses aveux au lecteur, car elle ne l'entraîne pas seulement avec elle lors de ses déplacements mais aussi chez elle, dans son univers le plus intime, à son bureau d'écrivain comme derrière les fourneaux et à table. Elle se concède en nous faisant partager ses sentiments, ses inquiétudes, ses émotions et nous laisse découvrir une vie passionnante, de curiosité et de générosité mais aussi une vie d'épreuves surmontées par la gourmandise: pour les mots, les hommes, les histoires et les mets. 